\title{
Expansion and Enhancement in Knowledge Organization Courses: Response to the Requirements of the Digital Environment
}

\author{
Abdus Sattar Chaudhry \\ Department of Information Studies \\ College of Social Sciences \\ Kuwait University, Kuwait
}

\begin{abstract}
The research work in this paper focuses on the changes that are needed in teaching approaches, specific in knowledge organization courses respond to the requirements of the digital information environment. Views of faculty were sought through a web-based survey on treatment and placement of new themes and relevance of frequently used tools. Shift in teaching focus to make to the learning needs of the new generation of students and professionals were also presented.
\end{abstract}

\section{Introduction}

Comprehensive presence of internet is a major component of the digital information environment. This is seen in the form of websites, cloud services, search engines, social media outlets, mobile apps, and other web-based resources and services. Students and workers in the digital environment have access to more information than ever before. They are increasingly mobile and globally connected. There appears a need to change the way teaching is done.

In other words re-thinking and re-visioning of education is needed to address the needs of students in the new environment. The process of re-visioning will challenge our practices requiring us to embrace pedagogical models that engage our students in learning. We need practices that better leverage the potential of the new technologies - practices that encourage flexible and personalized learning experience. This is also applicable to information education and teaching of knowledge organization courses.

Organizations are expected to use new operating models to emerge globally and provide needed services in the digital transformation of economies. This had led to launch of new services and review of current practices to stay relevant and responsive to the imperatives of the new environment. Practitioners need relevant and appropriate competencies to take advantage of new opportunities in the digital context, given the challenges of the emerging socio-economic environment. Accordingly, educational institutions are expected to be more responsive to changing trends. As in other fields, information education programs are expected to make fundamental changes to respond to the new imperatives. These fundamentals changes will occur with appropriate re-visioning of education. The paper focuses on the following:

- Introduction of new themes and treatment and placement of new topics in appropriate courses.

- Changes desirable in current approaches for teaching knowledge organization courses to address issues related to digital information.

- Possible shift in teaching focus to make courses more useful for effective learning for new generation of students and professionals.

Knowledge organization (KO) is an important component of information studies education. KO has always been considered a core competency for information professionals. In the traditional environment, knowledge organization courses were taught in a special context. These focused on facilitating access to special collections for defined groups of users and supporting information organization functions (cataloging and classification), KO courses emphasized using international standards to support exchange of records between information institutions. Standards were employed through specialized tools designed for specific functions. New environment requires a shift in this context by expanding the scope of course contents and making changes in teaching approaches.

\section{Literature Review}

Several studies addressed the challenges in information education and teaching of $\mathrm{KO}$ courses and pointed out need for changes in relevant areas. Morgan and Bawden, [1] discussed about the divergence between the views of educators and employers and professional associations about the need for expertise in information and knowledge organization among information professionals. All groups regard theoretical and conceptual knowledge 
as more important than practical skills. Cataloging and classification are central in formal education courses and are considered an important role for continuing professional development.

Saumure and Shiri [2] reviewed the dominant knowledge organization trends in the pre- and postweb eras. They reported that the focus has shifted since the advent of the web. New content areas such as metadata denoted a shift in knowledge organization trends. Earlier the literature was related in large part to indexing and abstracting. Now cataloging and classification issues dominate the landscape. Aytac et al. [3] discussed emerging trends in information and knowledge organization curriculum. They recommended that objective analysis of current courses should be conducted to assess whether these course contents are in line with the requirement for organizing web-based and digital information resources,

Hjorland [4] asserted that expertise developed for knowledge organization will be applied and adapted in the digital environment. He suggested that changes were necessary in competencies and skills to respond to the digitization initiatives.

Chaudhry [5] reflected on the need to expand the scope of the area of knowledge organization. He recommended that we need to critically examine if the teaching was in line with the evolving areas of expertise required to handle the information work in the digital economy. Alajmi and Rehman [6] surveyed courses being taught in ALA-accredited LIS programs with a view to examine the nature of courses and adequacy of coverage of relevant topics. Rehman and Alajmi [7] identified most frequently taught topics on knowledge organization in major information studies programs. They raised questions about the need and relevance of knowledge organization topics to the digital environment. They also highlighted need for appropriate strategies for handling the challenges created by new developments.

In addition to the course or subject specific aspects, digital information environment requires review of learning styles and re-thinking about the academic programs. Molnur [8] highlighted that practical methods of atypical forms of learning such as e-learning, networked based community learning and use of cloud-based services are more useful in the digital environment. Smith [9] the future of LIS education and highlighted the need for re-visioning of IS education. She asserted that we need to critically re-examine the ways we teach. We need to objectively review if our teaching approaches were in line with the learning needs of the new generation of students.

Review of above studies indicated that enhancements in the area of knowledge organization were essential to accommodate the changes brought by digitalization. Most studies suggested review of course contents and program structures. They highlighted that changes in course titles and addition of some topics might not be enough. These studies have stressed that well thought out changes will be necessary to redesign the curricula and input from relevant faculty will be crucial in these efforts. The study being reported in this paper was designed with this framework in view.

\section{Data Collection}

Faculty members who are currently teaching knowledge organization courses or have taught such courses in the past were invited to participate in the study. Potential participants were identified by browsing websites of information studies programs worldwide. Email messages were sent to faculty members to invite them to participate in the study. They were requested to fill-up an online questionnaire to give their input about the relevance and need of new themes and their placement in core or elective courses. Their views were also sought on possible shift in the teaching focus and to make these courses relevant to the digital environment.

A total of 52 faculty members from different information studies programs from seven countries responded. The respondents were also asked if they would like to participate in the follow up interviews in the second phase of the study. These interviews will be conducted in the second phase of the study.

\section{Findings}

Previous studies have identified topics and themes which are important for the digital environment. Faculty views were sought on these themes. They were asked to give opinion on the need of these themes with regard to the requirements of the digital environment. They were also asked on the possible treatment and placement of these topics.

Most respondents considered that two of the seven listed themes were not needed. These include 'folksonomies' and 'personal information management'. Nine percent chose the theme of 'topic maps' in the list not needed to be included in the new courses. Respondents gave their opinion for the listed themes in terms of their treatment as topics in modules, modules in courses, and/or introduction of full core or elective courses to provide adequate coverage. Table 1 lists the themes which were considered suitable for starting an elective or a core course. It is interesting to note that majority of the respondents considered only two themes as candidates for core course. Information architecture was also selected as a candidate for most of the participants. The other two themes picked up to be selected for full course (elective) are taxonomies and ontology. Table 2 presents opinions of the faculty 
about treatment of selected themes to be considered for topic or modules.

Table 1. Themes for Full Courses

\begin{tabular}{|l|l|c|l|}
\hline$\#$ & \multicolumn{1}{|c}{ Theme } & Core & Elective \\
\hline 1 & $\begin{array}{l}\text { Information } \\
\text { Architecture }\end{array}$ & 38.2 & 21.3 \\
\hline & $\begin{array}{l}\text { Personal } \\
\text { Information } \\
\text { Management }\end{array}$ & 19.2 & 9.2 \\
\hline 3 & Topic maps & 16.3 & 8.5 \\
\hline 4 & Ontology & 14.8 & 12.9 \\
\hline 5 & Taxonomies & 12.9 & 14.8 \\
\hline 6 & Folksonomies & 12.7 & 0.0 \\
\hline 7 & Social Tagging & 6.4 & 3.3 \\
\hline
\end{tabular}

Table 2. Placement of New Themes

\begin{tabular}{|c|c|c|c|}
\hline \multicolumn{4}{|c|}{$\mathrm{N}=52$} \\
\hline \# & Theme & Topic & Module \\
\hline 1 & Folksonomies & 25.0 & 8.5 \\
\hline 2 & Social tagging & 18.3 & 19.5 \\
\hline 3 & Ontology & 13.3 & 15.8 \\
\hline 5 & Taxonomies & 13.3 & 15.8 \\
\hline 5 & Topic maps & 11.6 & 18.2 \\
\hline 6 & $\begin{array}{l}\text { Personal information } \\
\text { management }\end{array}$ & 10.0 & 13.4 \\
\hline 7 & Information architecture & 6.6 & 7.3 \\
\hline
\end{tabular}

As shown in Table 2, majority of the respondents recommend that themes of social tagging and folksonomies are the areas that can be taught as either topics in module or modules in a course. course or as a topic in a module. One respondent mentioned most of the listed themes were already covered in introductory courses.

The following additional themes were also suggested by respondents for consideration as new topics for different courses to be offered in information studies programs to respond to the requirements of the digital information environment:

- Knowledge representation

- Resource Description Framework

- Text analysis

- Semantic web

- Flexible data management tools

- Thesaurus and subject approach

- Knowledge management
In the opinion of this researcher, treatment of the new themes as topics may not provide adequate coverage of these themes needed to prepare information professionals to handle knowledge organization work in the digital environments. This needs to be discussed further in the follow up interviews with the faculty members.

\subsection{Relevance of Tools}

Resource Description and Access (RDA), Machine-Readable Cataloging (MARC), Library of Congress Subject Headings (LCSH), and Dewey Decimal Classification (DDC) have been used for information organization work and subsequently taught in information studies programs. Several studies have pointed that these is a need to critically examine if these tools are still adequate to provide required support for organization of networked and digital information resources. Faculty members to asked to reflect on the relevance of these tools. Their responses are summarized in Table 3.

Table 3. Relevance of Tools

\begin{tabular}{|c|l|l|c|c|c|}
\hline$\#$ & Statmt & RDA & MARC & LCSH & DDC \\
\hline 1 & Relevant & 88.6 & 70.4 & 75.0 & 59.1 \\
\hline 2 & $\begin{array}{l}\text { Need to } \\
\text { enhance }\end{array}$ & 44.7 & 63.2 & 34.4 & 44.7 \\
\hline 3 & Re-tool & 33.0 & 54.5 & 48.4 & 51.5 \\
\hline 4 & $\begin{array}{l}\text { To build } \\
\text { new tool }\end{array}$ & 67.7 & 35.5 & 70.9 & 35.4 \\
\hline 5 & Replace & 29.2 & 45.8 & 50.0 & 41.6 \\
\hline
\end{tabular}

As shown in Table 3, most tools are still considered relevant. However, faulty expressed that fundamental changes are desirable to re-tool them. Respondents also appear to be aware of the potential of these tools to build new tools. Percentages are higher for RDA as this has already go through fundamental changes.

\subsection{Shift in Teaching Strategies}

Professionals in the digital environment belong to different category of learners. Their ideal learning environment involves lectures and more collaboration with peers. Group-based projects that emulate the work environment are ideal for these learners. They need to experience change in delivery formats to maintain interest. Teaching spaces should be more collaborative which combine digitally enabled learning spaces and support services.

It is difficult for students to absorb all of the information in a lecture. More effective approach will be to get students actively thinking and learning. This is particularly important in knowledge 
organization courses where a large part of the work is of practical nature.

Respondents were asked to reflect on current teaching approaches. They were asked to indicate their agreement about these approaches as reflected by a set of statements. Their responses are summarized in Table 4.

Table 4. Teaching Strategies $\mathrm{N}=52$

\begin{tabular}{|c|l|l|}
\hline$\#$ & \multicolumn{1}{|c|}{ Change Desired } & Mean \\
\hline 1 & $\begin{array}{l}\text { Change focus from library } \\
\text { collections to individuals }\end{array}$ & 4.12 \\
\hline 2 & Encourage use of multiple systems & 3.91 \\
\hline 3 & $\begin{array}{l}\text { Shift from using tools to } \\
\text { constructing tools an designing } \\
\text { systems }\end{array}$ & 3.45 \\
\hline 4 & $\begin{array}{l}\text { Change the mentality of how it was } \\
\text { done in the past }\end{array}$ & 3.45 \\
\hline 5 & $\begin{array}{l}\text { Encourage flexibility and openness } \\
\text { rather than adherence to standards }\end{array}$ & 3.33 \\
\hline
\end{tabular}

Drawn from the literature, five statements were presented to respondents and they were asked to indicate their agreement with these statements. These statements indicated the traditional teaching approaches that focused on organization of information resources in library collections; emphasized adherence to standards; and encouraged work according to established past practices. Only for one statement that recommended that teaching of knowledge organization courses should go beyond library collection yielded mean score above 4. For the remaining four statements which were about relaxation in adherence to standards and use of different schemes and systems, mean scores agreeing with these statements were below 4 .

As shown in Table 4, faculty members overwhelming supported a shift from organization of institutional collections to support information resources organizations by individual researchers and knowledge workers. However, the faculty members who teach courses are knowledge organization ae in favor of standardized procedures and adherence to past practices. There is a need to create a learning environment where relevance of information for work can be clearly seen. Professionals in the digital environment would like to get engaged in hands-on or application-based case studies, where new knowledge is discovered and synthesized actively between group members.

Mehta and Downs [10] suggest that professionals in the digital environment like techniques that connect them to the professional community. Therefore, it is important that strategies are deployed for sharing stories from teachers and students' work environment are discussed. They expect that instructors will spend more time on activities that build connections between students and link academic material to work situations.

\section{Conclusions}

Faculty members supported the idea to expand the scope of knowledge organization courses. There appears to be an agreement that core courses should be introduced in the areas of personal information management and information architecture to respond to the needs of organization of knowledge resource in the digital environment. Faculty was also supportive of encouraging use of multiple systems and changing the context of teaching these courses from institutional to individual context.

Contrary to general impressions that knowledge organization tools (RDA, LCSH, MARC, and DDC) are no more relevant as these were developed more than 100 years and were designed to handle traditional information sources. Participants of this study considered that these tools are still relevant and are still needed to organize information resources. Faculty members, however, did point out the need for re-tooling some of the commonly used tools to make these useful for digital information resources. They also indicated that these tools have great potential for constructing new tool and designing digital information systems.

While faculty members appear to be supportive of teaching the teaching focus to make these courses more useful for organizing information sources, they were cautious about making courses flexible and open and appear to prefer conservative approach for changing from past practices to more open approaches to teach knowledge organization courses.

Faculty input on knowledge organization courses will be helpful in design and assessment of curriculum in information studies programs. The findings of the study will also be useful in designing professional continuing education programs to build required competencies in working information professionals. There is also a need to pay attention to create better and more supportive learning environment.

Findings are expected to be helpful in making decisions for placement of knowledge organization topic in different types of courses. However, it is desirable that some responses are further discussed with faculty members in interviews or focus group discussions to gain insights. This will be done in the second phase of the study. Interviews and focus group discussions will be conducted to gain further insights of relevant issues.

Instant and regular feedback also plays an important role in teaching professionals in the digital environment. Al-Bashir, Kabir, and Rahman, [11] Feedback significant effect in professionalizing teaching in the higher education level. Feedback is considered as a difficult issue as most of the 
instructors still use traditional approaches to feedback. Traditional feedbacks may not help much in improving the learning experience. There is a need to re-think about the feedback providing focusing on motivation, encouragement as well as assessment. Modern technology-based way of proving feedback can help in improving learning experience and make learning more effective. Regular feedback can help in professionalism.

Feedback in the form of appreciation (to motivate), coaching (to increase knowledge), and evaluation (to line-up expectations) will be an important element in desirable teaching strategies. Constant and immediate feedback is needed for information professionals particularly to those who are performing knowledge organization functions.

\section{References}

[1] Morgan, J. and Bawden, D., (2006). Teaching knowledge organization: educator, employer and professional association perspectives. Journal of Information Science, 32(2), 108-115.

[2] Saumure, K. and Shiri, A., (2008). Knowledge organization trends in library and information studies: a preliminary comparison of the pre- and post-web eras, Journal of Information Science, 34(5), 651-666.

[3] Aytac, S., Kipp M., Neal, D., and Hsieh-Yee I., (2012). Emerging trends and knowledge organization and information organization courses curriculum. Proceedings of the American Society for Information Science and Technology. DOI: 10.1002/meet.2011.1 4504801079.

[4] Hjorland, B., (2013). Theories of Knowledge Organization. Keynote address delivered at the 13th Meeting of the German ISKO (International Society for Knowledge Organization), 19 March 2013.

[5] Chaudhry, A. S., (2016). Re-conceptualization of knowledge organization: Imperatives of networked resources and digitization. International Journal of Knowledge Content Development and Technology, 6(2), 93-108. http://dx.doi.org/10.5865/IJKCT.201 6.6.2.093

[6] Alajmi, B. and Rehman, S., (2016). Knowledge Organization Trends in Library and Information Education: Assessment and Analysis. Education for Information. 32(4), 411-422.

[7] Rehman, S. and Al-Ajami, B., (2017). Knowledge organization content in graduate courses. Library Review. 66(1/2). DOI 10.1108/LR-03-20160028
[8] Molnar, G., (2015), Teaching and learning in the digital modern environment. IEEE $13^{\text {th }}$ International Symposium on Applied Machine Intelligence and Informatics (SAMI). https://www.se $\mathrm{m}$ an ticscholar.org/paper/Teaching-and-learning-inmodern-digital-environment-Molnar/27e5a142b8c56 27df73ebb9d2ccdb927801d343d (Access Date: Feb 11, 2018).

[9] Smith, L., (2017). Future of LISE. https://ischool.illinois.edu/news-events/news/2016/ 01/future-lis-education (Access Date: Apr 21, 2018).

[10] Mehta. S. and Downs, H., (2016). Six Strategies for Digital Learning Success. Center for Creative Leadership. https://www.ccl.org/wp-content/uploads /2016/05/Digital-Learning-Success-White-Paper-1. pdf (Access Date: Apr 23, 2018).

[11] Al-Bashir, M., Kabir, R., and Rahman, I., (2016). Value and effectiveness of feedback in improving students' learning and professionalizing teaching in higher education. Journal of Education and Practice, 7(16). https://files.eric.ed.gov/fulltext /EJ1105282.pdf (Access Date: May 23, 2018).

\section{Acknowledgement}

This research was supported by Kuwait University vide project grant number IO01/17. 